\title{
Mechanisms of RDH12-Induced Leber Congenital Amaurosis and Therapeutic Approaches
}

\author{
Anne Kasus-Jacobi ${ }^{1}$, Lea D. Marchette ${ }^{1}$, Catherine $\mathrm{Xu}^{1}$, \\ Feng Li ${ }^{1}$, Huaiwen Wang ${ }^{1}$ and Mark Babizhayev ${ }^{2}$ \\ ${ }^{1}$ Oklahoma University Health Sciences Center \\ Innovative Vision Products, Inc. \\ USA
}

To Finley: You made this work very special to us.

\section{Introduction}

Retinal dystrophies are characterized by the degeneration of vision-supporting photoreceptor cells of the retina, leading to irreversible blindness. It is a heterogeneous group of diseases that can be caused by mutations on more than 150 identified genes with diverse functions (http://www.sph.uth.tmc.edu/Retnet/home.htm). Retinal dystrophies can be classified based on whether the rod or the cone photoreceptor cells are affected first, and based on the onset and progression of vision loss [1]. Leber congenital amaurosis (LCA) is in clear contrast with other inherited retinal dystrophies in that both rod and cone photoreceptor cells are affected from the onset of the disease [1]. The second major characteristic of LCA is that the progression to complete blindness is fast, making it the most devastating form of inherited retinal dystrophies [1]. In most cases, visual handicap is diagnosed before one year of age and progresses to legal blindness in early adulthood [2]. Other signs of the disease are an extinguished or severely reduced scotopic and photopic electroretinogram, absent or diminished pupillary response to light, and nystagmus (roaming eye movements) [3]. It is a rare disease, affecting approximately 1:30,000 people worldwide but it is the first cause of inherited blindness in children [2].

During the past 15 years, our understanding of the genetic basis of LCA has greatly progressed [1]. Today, 14 different genes causing LCA have been identified [1]. Together they are responsible for approximately $75 \%$ of LCA cases, the remaining $25 \%$ of LCA cases being caused by mutations in unidentified genes. The identified LCA-causing genes are expressed in various cell types of the retina and are involved in a wide variety of developmental and physiological pathways [1]. Because the disease is induced by mutation on a single gene, LCA patients are potentially good candidates for gene replacement therapy. In recent years, exciting results have been obtained in clinical trials for LCA caused by mutations on the RPE65 gene (LCA2), representing 3 to $16 \%$ of LCA cases [4]. Several other LCA-causing genes have received proof-of-concept validation for gene therapy in animal models [1]. We can anticipate that in the following years, patients with LCA induced by mutations on these genes will undergo clinical trials for gene replacement therapy. 
In this chapter, we will concentrate on LCA13 caused by mutations in the RDH12 gene. This gene encodes for an enzyme of the short-chain dehydrogenase/reductase superfamily. It was named retinol dehydrogenase 12 (RDH12) based on its similarity with the RDH11 enzyme (Figure 1) [5]. Gene replacement therapy is not currently available for LCA13 patients and may not be for several years. Thus, any alternative therapeutic approach would be beneficial. We will review our and other's findings regarding the function of RDH12, providing new insight into the mechanism of RDH12-induced LCA. We will discuss how understanding the role of RDH12 is allowing the development of alternative therapeutic strategies to gene replacement therapy for patients with LCA13. Finally, we will describe our encouraging preliminary results obtained in a mouse line with disrupted $R d h 12$ gene, using an imidazole-containing peptide derivative, which could be rapidly developed into an effective therapeutic strategy to preserve retinal structure and function in LCA13 patients.

RDH12 ----MLVTLGLLTSFFSFLYMVAPSIRKFFAGGVCRTNVQLPGKVVVITGANTGIGKETARELASRGARVYIACRDVLKG 76 RDH11 MVELMFPLLLLLLPFL--LYMAAPQIRKMLSSGVCTSTVQLPGKVVVVTGANTGIGKETAKELAQRGARVYLACRDVEKG 78

RDH12 ESAASEIRVDTKNSQVLVRKLDLSDTKSIRAFAEGFLAEEKQLHILINNAGVMMCPYSKTADGFETHLGVNHLGHFLLTY 156 RDH11 ELVAKEIQTTTGNQQVLVRKLDLSDTKSIRAFAKGFLAEEKHLHVLINNAGVMMCPYSKTADGFEMHIGVNHLGHFLLTH 158

RDH12 LLLEQLKVSAPARVVNVSSVAHHIGKIPFHDLQSE-KRYSRGFAYCHSKLANVLFTRELAKRLOGTGVTTYAVHPGVVRS 235 RDH11 LLLEKLKESAPSRIVNVSSLAHHLGRIHFHNLQGE-KFYNAGLAYCHSKLANILFTQELARRLKGSGVTTYSVHPGTVQS 237

RDH12 ELVRHSSL------LCLLWRLFSPFVKTAREGAQTSLHCALAEGLEPLSGKYFSDCKRTWVSPRARNNKTAERLWNVSCE 309 RDH11 ELVRHSSF------MRWMWWLFSFFIKTPQQGAQTSLHCALTEGLEILSGNHFSDCHVAWVSAQARNETIARRLWDVSCD 311

RDH12 LLGIRWE--------- 316

RDH11 LLGLPID-------- 318

Fig. 1. Alignment of human RDH12 and RDH11 sequences. Residue numbers are shown on the right. Identical residues are boxed. Overbars denote the two signature sequences for the superfamily of short-chain dehydrogenase/reductases [6].

GenBank $^{\mathrm{TM}}$ accession numbers for human RDH12 and RDH11 are NP_689656 and CAG33461, respectively. Stretches of NH2-terminal hydrophobic residues predicted to be inserted in the membrane are underlined.

\section{RDH12 and Leber Congenital Amaurosis}

In 2004, mutations in the RDH12 gene were found in a subset of LCA patients [7,8]. Since then, more than 30 RDH12 mutations have been found in the homozygous or compound heterozygous state in LCA13 patients [7-11]. LCA13 is inherited in an autosomal recessive manner and represents about $4 \%$ of all LCA cases [2]. LCA13 appears to share a common clinical picture with other types of LCA characterized by a poor visual function in early life, followed by a progressive decline due to both rods and cones degeneration [9]. 
Interestingly, when compared with the RPE65-mutant retina that has a relatively well preserved structure with a disproportionate loss of photoreceptor function (as measured in 4 LCA2 patients; ages 17, 19, 19 and 23), the structure of RDH12-mutant retina appears disrupted at much younger ages (measured in 4 LCA13 patients; ages 8, 11, 13 and 21) [12].

A number of RDH12 mutations leading to LCA have been biochemically evaluated by expressing the mutants in cultured cells and by measuring the enzymatic activities of the recombinant enzymes [7-11]. These studies have shown that mutations in RDH12 result in decreased or abolished enzymatic activity due to a lower affinity for the substrate or a lower affinity for the coenzyme and/or to a decreased specific activity. In addition, most of RDH12 mutations resulted in low steady-state levels of the mutant proteins in cells [11, 13]. It was hypothesized that these mutants could be recognized as misfolded and targeted for accelerated degradation by the ubiquitin-proteasome system [13]. These studies strongly suggest that the loss of RDH12 function is the primary event causing the development of LCA13 phenotype (i.e. rapid loss of photoreceptor function and disruption of retinal structure). Thus, to determine the triggering event in LCA13 pathogenesis, and because RDH12 is an enzyme, the fundamental question is: what is the nature of the RDH12 substrate?

\section{Enzymatic activity of RDH12}

RDH12 is an oxidoreductase enzyme of the short-chain dehydrogenase/reductase superfamily [5]. Its substrate and coenzyme specificities have been elucidated in vitro [5, 14]. RDH12 was found to reduce all-trans retinal and other retinaldehydes (in cis configurations) to corresponding retinols, using the reduced form of nicotinamide adenine dinucleotide phosphate as cofactor [5, 14]. In addition, various aldehydecontaining molecules, including 4-hydroxynonenal (4-HNE), were found to be reduced by RDH12 to corresponding alcohols [14]. Thus, RDH12 has a double substrate specificity for all-trans retinal (and other retinaldehydes) and for 4-HNE (and other toxic aldehydes). In addition, the possibility that RDH12 could have other -yet unknown- substrates cannot be ruled out.

The existence of two groups of substrates for RDH12 suggests that this enzyme could have two distinct physiological functions in vivo. As mentioned, mutations of RDH12 associated with LCA resulted in a decreased enzymatic activity of RDH12, inhibiting the reduction of all-trans retinal and $4-\mathrm{HNE}$ to the corresponding alcohols in vitro $[7,10,11$, 15].

\section{Possible RDH12 function(s) in the retina}

RDH12 is abundantly expressed in rod and possibly cone photoreceptor cells in the retina [16-19]. These cells are photosensitive; they detect the presence of photons through the 11-cis retinal chromophore bound to opsin protein (forming the photosensitive rhodopsin). When photobleaching of rhodopsin occurs, light isomerizes 11-cis retinal to all-trans retinal, which then dissociates from opsin. This photoisomerization is the initial event that triggers the visual transduction pathway, activation of second order neurons, and eventually transmission of the signal to the brain. Under constant illumination, 11-cis retinal has to be 
replaced (recycled) and all-trans retinal has to be removed from the surrounding of opsin so that photoreceptor cells continue to have an optimum sensitivity to light. The retinoid or visual cycle is the multi-step biochemical pathway that allows the recycling of 11-cis-retinal. The retinol dehydrogenases RDH8 (expressed in photoreceptor cells) and RDH5 (located in retinal pigment epithelium cells) were shown to directly participate in this essential pathway for maintenance of normal vision [20]. A possible function for RDH12 could thus be to reduce all-trans retinal, duplicating the RDH8 function, to keep photoreceptor cells in a state of high sensitivity to light.

We proposed another possible function for RDH12 in photoreceptor cells, in relation with its ability to reduce 4-HNE [15]. Reactive oxygen species formed within the mitochondria as byproducts of the electron transport chain can directly attack polyunsaturated fatty acids and initiate an auto-amplified chain reaction of lipid oxidation in cellular membranes. This causes the degradation of polyunsaturated fatty acids into a variety of oxidized products, including short- and medium-chain reactive aldehydes such as malondialdehyde, 4hydroxyhexenal, and 4-HNE [21]. 4-HNE is the oxidation product of $\omega-6$ arachidonic and linoleic fatty acids and is the most abundant and toxic end-product of lipid oxidation found in tissues [21-23]. It reacts readily with histidine, cysteine, and lysine to form Michael's adduct with these residues [24]. Oxidative modification of protein by 4-HNE leads to a variety of effects including inhibition of enzymatic activities; inhibition of protein functions; targeting of modified proteins for degradation; inhibition of protein, RNA, and DNA synthesis; cell cycle arrest; and apoptosis [21, 22, 25, 26]. When 4-HNE is reduced to the corresponding alcohol dihydroxynonene, its ability to form toxic adduct with proteins is abolished. Thus, we proposed that a possible function for RDH12 in the retina could be to detoxify 4-HNE by reducing it to dihydroxynonene [15].

When there is a loss of enzymatic function in cells, the substrate of the inactivated enzyme accumulates while the product of the reaction decreases. The next question is then whether it is the accumulation of substrate(s) or the disappearance of product(s), or both, that triggers the LCA13 phenotype. All-trans retinol, the product of all-trans retinal reduction, is not absolutely required for visual function because it is constantly supplied to the retinal pigment epithelium cells from the circulating blood. Therefore the most probable hypothesis is that accumulation of the substrate (all-trans retinal) rather than lack of product (all-trans retinol) might cause the retinal phenotype in LCA13 patients. Dihydroxynonene, the product of 4-HNE reduction, is not known to mediate any crucial biological function therefore in this scenario also, it seems that accumulation of the toxic substrate (4-HNE) rather than lack of product (dihydroxynonene) would cause the LCA13 phenotype.

\section{Utilization of the Rdh12 knockout mouse to determine the physiological substrate of RDH12}

Identifying possible substrates for an enzyme in vitro is not enough to demonstrate that they are physiological substrates. In vivo, other considerations such as the localization and concentration of substrate relative to that of the enzyme are very important. Locations of the enzyme and substrate have to overlap and the substrate concentration has to be within a specific range for the enzymatic reaction to take place in vivo. The next step is thus to determine if there is accumulation of all-trans retinal and/or 4-HNE in the retina, in absence 
of RDH12. Mice with disrupted $R d h 12$ gene have been generated $[16,19]$ and they have been useful to determine what substrate of RDH12 accumulates in the retina.

After bleaching of rhodopsin, a moderate delay in all-trans retinal clearance was found in the $R d h 12$ knockout retina $[19,27,28]$. To explain the existing but surprisingly small delay in all-trans retinal clearance, it has been argued that RDH12 is located only in the inner segment of photoreceptor cells, while rhodopsin is located only in the outer segment. Thus, it was proposed that instead of participating directly (with RDH8) to the reduction of all-trans retinal released in the outer segment, RDH12 could reduce only a small portion of all-trans retinal overflowing to the inner segment after bleaching of rhodopsin $[27,28]$.

In our study, we found that retinas of both albino [15] and pigmented Rdh12 knockout mice (Figure 2) accumulated more 4-HNE-modified proteins than the corresponding wild-type animals on the same genetic background. As shown in Figure 2, pigmented knockout mice have significantly more retinal 4-HNE-protein adduct than the wild-type when exposed to bright light, a condition that induces oxidative damage. Similarly, in the BALB/c albino mice, 4-HNE-protein adduct was $60 \%$ higher in $R d h 12$ knockout than in wild-type retinas in 2-month old animals raised under dim cyclic light [15]. These results support the hypothesis that 4-HNE is a physiological substrate of RDH12 in rod inner segments.

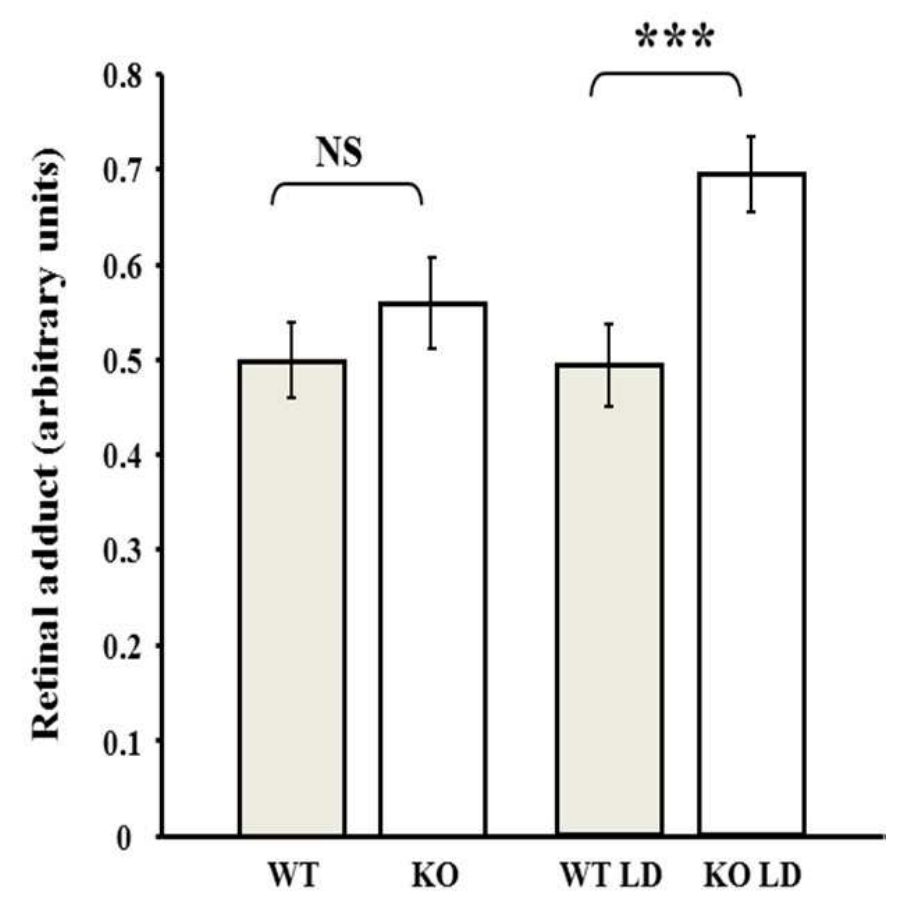

Fig. 2. RDH12 protects against light-induced adduct formation in pigmented mouse retina. Graph shows results for 6 mice per group. Littermates of wild-type and Rdh12 
knockout mice were raised under dim (5-10 lux) cyclic light for 8 weeks. Control wild-type (WT) and knockout (KO) mice were killed $5 \mathrm{~h}$ after the (dim) light started. Light damaged (WT LD and KO LD) mice were killed after $48 \mathrm{~h}$ exposure to bright light (3,000 lux), without prior dilation of the pupils. Dissected retinas were homogenized in T-PER buffer (Pierce), according to the manufacturer's instructions. Protein concentrations were measured and dot blot analyses were carried out as described to quantify retinal adduct [15]. Equal aliquots $(5 \mu \mathrm{g})$ of retinal protein were applied to a 96-well dot blot apparatus (Bio-Rad) and then transferred to a nitrocellulose membrane by vacuum filtration. Sample loading was monitored by staining the membrane with Ponceau red (Sigma). Membranes were blotted over night with a 1:1000 dilution of anti-HNE antibody coupled with horseradish peroxidase (abcam). Signals were quantified using SuperSignal West Femto Chemiluminescent Substrate (Pierce) and the digital Kodak Image Station 4000R. Error bars denote SEM and Student's $t$ test was used for significance.

NS, not significant $(p>0.05) ;{ }^{* *}, p<0.0001$.

The conclusion of these studies is that at least two physiological substrates of RDH12 coexist in photoreceptor cells; namely all-trans retinal and 4-HNE. The clearance of both of these substrates is delayed in the $R d h 12$ knockout retina and it is now of crucial importance to determine which one, or if they can both, trigger the LCA13 phenotype.

\section{Limitations of the Rdh12 knockout mouse model to determine what substrate mediates photoreceptor damage}

The main limitation to further determine whether accumulation of all-trans retinal or accumulation of 4-HNE is the triggering event in LCA13 is that, unlike LCA13 patients, the $R d h 12$ knockout mouse does not develop a retinal phenotype [16, 19]. Thus the $R d h 12$ knockout mouse is not an appropriate model for LCA13. We propose two possible explanations for the differences between mouse and human phenotypes.

\subsection{Perhaps in mouse -but not in human- another enzyme is compensating for the loss of RDH12}

In addition to RDH12, RDH11 and RDH13 are located in the inner segment of mouse photoreceptors. RDH11 and 12 are integral membrane proteins. Both enzymes are inserted in the membrane through a stretch of $\sim 20 \mathrm{NH} 2$-terminal hydrophobic residues (Figure 1) [5, 29]. RDH13 does not contain this stretch of hydrophobic residues and is a peripheral membrane protein. In previous studies, we showed that RDH11 is localized in the Golgi apparatus in spermatocytes [29] and in various cultured cells (unpublished observation). We performed a subcellular fractionation of mouse retinal tissues through ultracentrifugation on sucrose gradient [30]. RDH12 was found in Golgi- and endoplasmic reticulum-enriched fractions and RDH11 was detected only in the Golgi-enriched fractions [31]. Another study showed that RDH13 is a mitochondrial enzyme, localized within the intermembrane space, and associated with the inner mitochondrial membrane [32]. These different subcellular localizations suggest a specific role for RDH13 in the mitochondria, another specific role for RDH12 in the endoplasmic reticulum, but a possible redundant function for RDH11 and RDH12 in the Golgi. In the Rdh12 knockout mouse photoreceptors, RDH11 may functionally compensate for RDH12 because these enzymes have overlapping localization and they have similar enzymatic activities and substrate specificities [17]. In humans on the other hand, RDH11 may not be 
expressed in photoreceptor cells [5] and thus may not compensate for the loss of RDH12 activity, possibly explaining the more dramatic phenotype in LCA13 patients.

\subsection{Perhaps bright light is triggering the phenotype resulting from disruption of RDH12 enzymatic activity}

Patients with LCA13 show an early disruption of their retinal structure [12]. The distorted laminar architecture of RDH12-mutant retinas seems to be a specific feature of some subtypes of LCA [12]. It has been suggested that such dysplastic retinal response could be triggered by some forms of photoreceptor damage induced by environmental conditions [12]. For example, light exacerbates the retinal dysplasia in a mouse model of LCA caused by CRB1 mutations (LCA8) [33, 34]. Interestingly, the Rdh12 knockout mice do not have a retinal phenotype when they are raised under a controlled dim (5-10 lux) cyclic light environment $[15,16,19]$. However, when they are challenged by exposure to bright light (3,000 lux for the Rdh12 knockout mice under the BALB/c background), the Rdh12-null photoreceptors appear significantly more sensitive than the wild-type cells to light-induced apoptosis $[15,19]$. Since $R d h 12$ knockout photoreceptors degenerate only after exposure to bright light but do not have a spontaneous degeneration when raised under controlled dim cyclic light, it is possible that similarly, the LCA13 patients have retinal degeneration because they are regularly exposed to very bright light intensities (i.e. outdoor light during a sunny day). Anticipation of dysplastic retinal response and greater understanding of the pathway that triggers it could lead to specific therapy to prevent this process in LCA13 patients. Without such prevention, the amount of salvageable retina might quickly become so low that any gene replacement therapy would not be worth attempting.

It is likely that the compensation by other RDHs combined with the controlled lighting environment, and anatomical differences between mouse and human retinas explain the absence of retinal phenotype in the $R d h 12$ knockout mouse, as opposed to the dramatic phenotype in LCA13 patients. In any case, it is difficult to use the Rdh12 knockout mice to determine what substrate of RDH12 accumulating in absence of enzyme induces a retinal phenotype, because there is no phenotype. Retinal damage can be induced by exposure to bright light but this treatment exacerbates the production of both substrates of RDH12 simultaneously so it is impossible to distinguish which one triggers the hypersensitivity of Rdh12-null photoreceptor cells to light-induced damage. In addition, we cannot exclude the alternative possibility that the hypersensitivity to light of the Rdh12-null photoreceptors is not the specific result of accumulation of RDH12 substrate(s) but rather due to a non-specific effect of the gene inactivation.

\section{Alternative strategy to determine what substrate mediates photoreceptor damage}

An alternative strategy is to experimentally induce the production of all-trans retinal and 4HNE simultaneously by exposure of the Rdh12 knockout mice to bright light, while at the same time decreasing the level of 4-HNE using a molecule that can specifically scavenge 4HNE and lower its concentration in the retina (Figure 3). This strategy allowed us to distinguish the relative participation of each substrate to the photoreceptor hypersensitivity to light. 


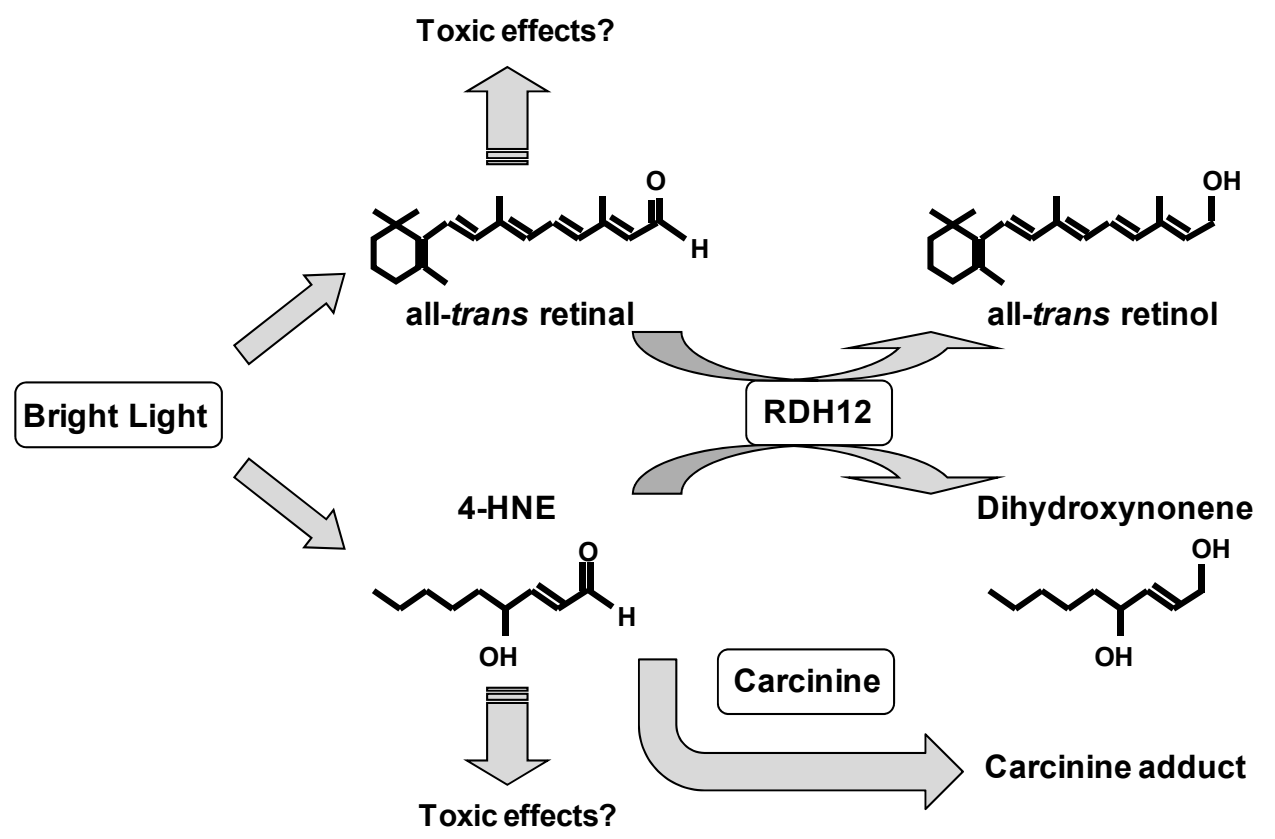

Fig. 3. Experimental strategy to determine what substrate of RDH12 mediates photoreceptor hypersensitivity to light-induced damage. Exposure to bright light exacerbates the production of both substrates (all-trans retinal and 4-HNE) simultaneously. In absence of RDH12, both substrates accumulate so it is impossible to distinguish which one triggers the hypersensitivity of photoreceptor cells to light-induced damage. Carcinine scavenges 4-HNE, forming 4-HNE-carcinine adduct, and thus can be used to lower 4-HNE independently of all-trans retinal. This allowed us to dissociate the effects of 4-HNE and all-trans retinal in the Rdh12 knockout mouse retina.

Carcinine ( $\beta$-alanyl-L-histamine) is a natural imidazole-containing peptide derivative that has antioxidant properties and can scavenge reactive aldehydes produced by lipid peroxidation $[35,36]$, thus preventing them from reacting with cellular proteins (manuscript submitted for publication). We have shown that intravitreal injection and systemic administration of carcinine protect wild-type photoreceptors from light-induced damage (manuscript submitted for publication). Photoreceptors are the first retinal cell type to show signs of damage after exposure to bright light. Light-induced apoptosis of photoreceptor cells is preceded by an increase of oxidative modification of retinal proteins $[17,37]$ and can be blocked by various types of antioxidants [38-40] including carcinine (manuscript submitted for publication). 
We used carcinine to lower 4-HNE independently of all-trans retinal and dissociate the effects of these two molecules in mouse retina. Incubation of carcinine with all-trans retinal in vitro does not lead to any modification of the all-trans retinal molecule as determined by high-performance liquid chromatography analysis (unpublished observation) but incubation with 4-HNE leads to the formation of an adduct between carcinine and 4-HNE as determined by high-performance liquid chromatography and mass spectrometry (manuscript submitted for publication). Thus, carcinine is not expected to lower the retinal level of all-trans retinal or other retinoids under normal conditions or during exposure to bright light.

As shown in Figure 4A, without carcinine treatment (phospate buffered saline-injected eye), exposure of wild-type mice to bright light induces a decrease of rod-mediated visual function by approximately $50 \%$ for both a- and b-waves (black bars). As expected, the $R d h 12$ knockout mice are more sensitive than the wild-type to light-induced damage, as shown by the 80 to $90 \%$ decrease of rod-mediated visual function for both a- and b-waves under the same conditions of light exposure (white bars). This result is consistent with previously published studies showing hypersensitivity of these knockout mice to light-induced damage [15].

Carcinine is expected to prevent light-induced damage mediated by oxidative stress and lipid peroxidation in photoreceptors. As shown in Figure 4A, with carcinine treatment (carcinine-injected eye), exposure of wild-type mice to bright light induce the decrease of rod-mediated visual function to about $25 \%$ loss instead of $50 \%$ loss without carcinine. In the $R d h 12$ knockout mice, carcinine completely prevents the decrease of rod-mediated visual function. The remaining rod-mediated visual function after light damage goes from $10 \%$ without carcinine to $100 \%$ with carcinine, demonstrating a considerably beneficial effect of carcinine in these mice. The reason(s) why carcinine seems to protect more efficiently $R d h 12$ knockout than wild-type photoreceptors is unknown. However, we can speculate that the disruption of $R d h 12$ creates a "mild stress" in photoreceptors, inducing maybe some alternative protective mechanisms. The combination of enhanced compensatory protection and carcinine protection could be a possible explanation for this apparent higher efficiency of carcinine in the knockout than in the wild-type photoreceptors.

As shown in Figure 4B, cone-mediated visual function is more affected in the knockout than in the wild-type mouse by exposure to bright light (in phospate buffered saline -injected eye), and complete protection was provided by carcinine in both wild-type and knockout mice (carcinine-injected eye).

The fact that carcinine completely prevents light-induced damage in the Rdh12 knockout mouse photoreceptors strongly suggests that the damage induced by light is mostly -if not only- mediated by oxidative stress and lipid peroxidation products accumulating in the Rdh12 knockout photoreceptor cells. However, a mirror experiment in which all-trans retinal is specifically lowered independently of 4-HNE would further confirm our conclusion, if there was no protection. To specifically lower all-trans retinal independently of 4-HNE, a possible approach could be to overexpress the RDH8 enzyme in the Rdh12 knockout photoreceptors because, as we have shown before, 4-HNE is not a substrate of RDH8 [29]. 
A- Rod response after light-induced damage

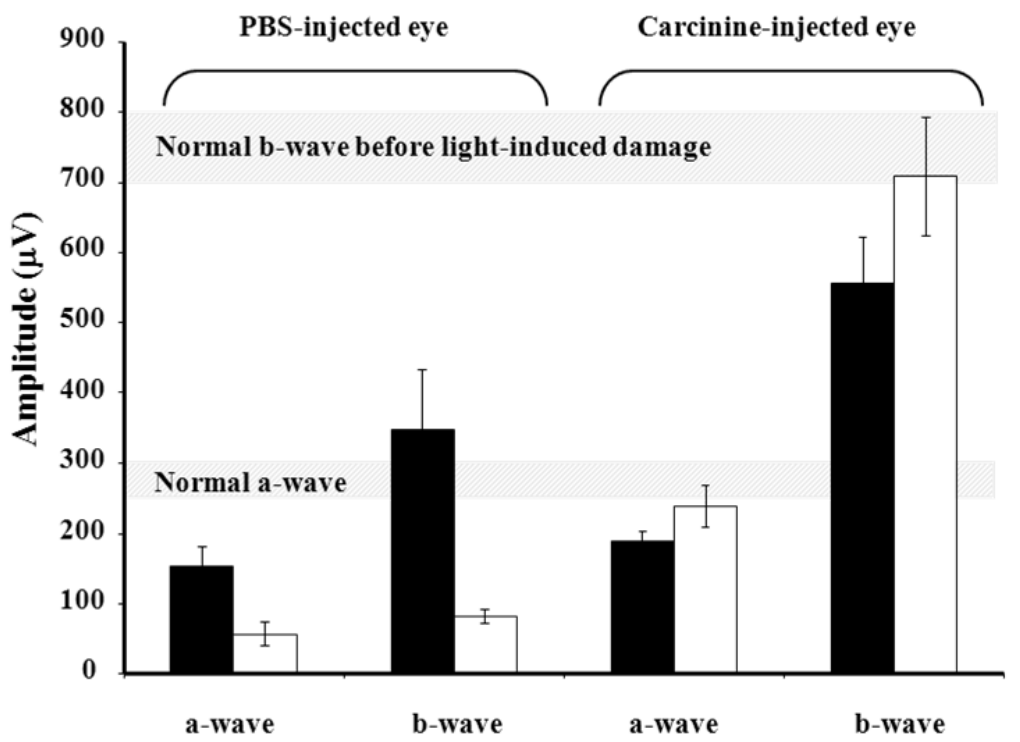

B- Cone response after light-induced damage

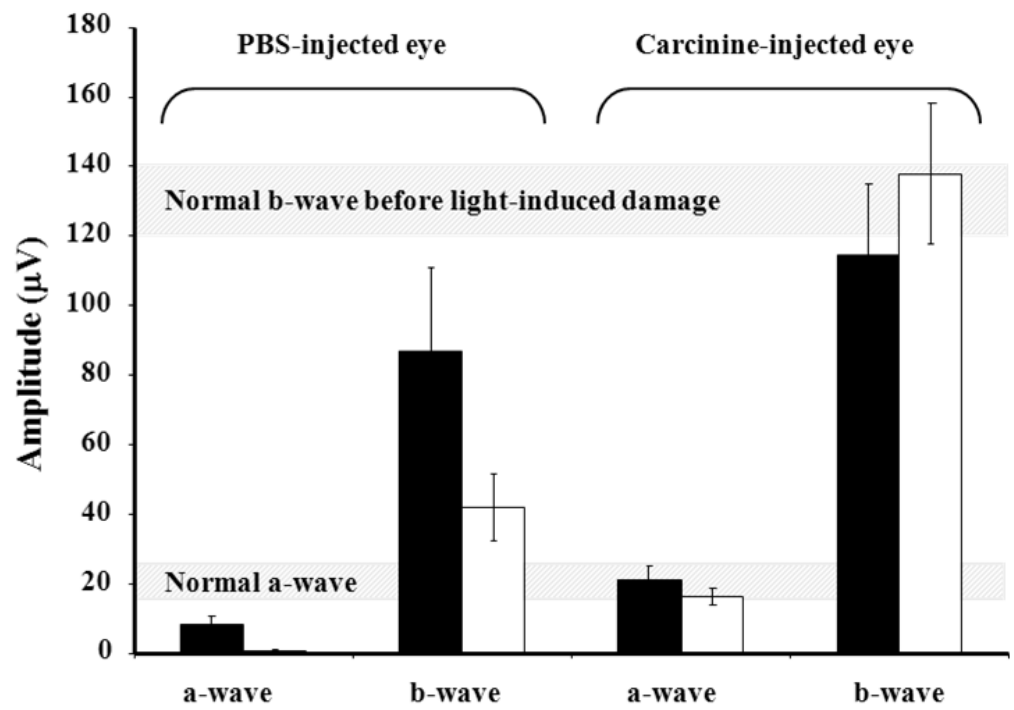

Fig. 4. Carcinine protects visual function against light-induced damage in wild-type and $R d h 12$ knockout mice. BALB/c mice were raised in dim cyclic light for 8 weeks. Each 
mouse was injected intravitreally in one eye with $1 \mu \mathrm{l}$ phospate buffered saline (PBS) and in the other eye with $1 \mu \mathrm{l}$ of $2 \mathrm{M}$ carcinine diluted in PBS. Mice were returned in dim cyclic light for $48 \mathrm{~h}$ before light damage was initiated. Light damage was then induced in mice by $5 \mathrm{~h}$ exposure to 4,000 lux of white fluorescent light. After light exposure, mice are returned in dim cyclic light for 7 days to allow the retina to clear all dead cells. A. Scotopic electroretinographies were performed using saturating flash intensity. The $a-$ and $b$-wave amplitudes of wild-type (black bars) and Rdh12 knockout (white bars) are plotted to quantify rod-mediated visual function. B. Photopic ERGs were then performed to measure cone-mediated visual function. The a- and b-wave amplitudes are plotted to quantify conemediated visual function. Graphs show averaged results from 7 mice and error bars indicate SEM. Grey boxes show normal a- and b-waves recorded from PBS-injected eyes in mice that were not exposed to bright light.

\section{Could decrease clearance of 4-HNE have toxic effects in photoreceptors?}

Effects of 4-HNE in cells and its association with disease states have been increasingly well documented [23, 41]. Studies have shown that low, basal levels of the lipid aldehyde are present in cells $(<5 \mu \mathrm{M})$, and at these concentrations, 4 -HNE acts as a signaling molecule [42, 43]. It can activate cell growth and survival as well as stress response mechanisms, such as mitogen activated protein kinases, detoxification mechanisms, and inflammatory response, and by this way prepare the cells to overcome acute stress (protective effects) [41]. Under conditions of oxidative stress, 4-HNE concentrations increase above physiological levels; in membranes it accumulates at concentrations of $10 \mu \mathrm{M}$ to $5 \mathrm{mM}$ in response to oxidative insult $[22,23]$. At such concentrations, the protective effect is lost; 4-HNE forms adduct with proteins inactivating their physiological functions, and activates intra cellular pathways promoting cell death $[22,23,41]$.

The presence of 4-HNE-derived epitopes, including 4-HNE-protein adduct, has been reported in a growing number of diseases, including diabetes, cardiovascular, autoimmune, and neurodegenerative diseases, such as Alzheimer's disease, Parkinson's disease and amyotrophic lateral sclerosis [23]. The consistently growing evidence of increased 4-HNE tissue/blood levels in a great variety of human diseases certainly suggests a pathogenetic involvement of the aldehyde in their clinical expression and possible progression [41]. Recent studies have implicated 4-HNE in the pathogenesis of atherosclerosis and Alzheimer's disease [22, 41].

Oxidative stress, which induces lipid peroxidation and 4-HNE production, has been abundantly described to induce photoreceptor cell death [44-47]. Whether toxicity is mediated by 4-HNE and other lipid peroxidation products is unknown. We hypothesize that 4-HNE-mediated toxicity is inducing the rapid loss of vision in LCA13 patients. This hypothesis is based on the following evidences: (1) in cell culture, enzymatically active RDH12 protects against 4-HNE-induced cell death, while enzymatically inactive RDH12 does not $[15,37]$. (2) Photoreceptor cells are particularly predisposed to oxidative stress because the retina has a high oxygen consumption, is chronically exposed to light, and contains several photosensitizers. This leads to an active production of reactive oxygen species. Furthermore, photoreceptors have a high content in polyunsaturated fatty acids, making their membranes particularly susceptible to lipid oxidation induced by reactive oxygen species. (3) In photoreceptor cells, 4-HNE production is induced by exposure to 
bright light, specifically in the inner segment, the compartment where RDH12 is located [15, 37]. (4) Disruption of RDH12 induces accumulation of 4-HNE-modified proteins in mouse retina, correlated with a hypersensitivity to acute light damage [15].

Taken together these results show a correlation between accumulation of 4-HNE in photoreceptor inner segments and loss of visual function, suggesting a possible cause-effect relationship. The cause-effect relationship has not been demonstrated but the mechanisms of 4-HNE toxicity have been abundantly documented in other cells types and disease states.

In LCA13 patients, it is likely that the loss of retinal structure and function is triggered by accumulation of RDH12 substrate(s). Two physiological substrates of RDH12 have been identified in vitro and in vivo. In absence of RDH12, accumulation of each of these substrates could theoretically mediate unwanted effects in photoreceptor cells.

\section{Carcinine - A possible therapeutic agent for LCA13?}

If 4-HNE is indeed involved in the LCA13 disease mechanism, then carcinine would clearly be beneficial based on its antioxidant and 4-HNE scavenging activities. Additionally, we recently found that carcinine has another effect that might be of significant interest for LCA13.

\subsection{Carcinine protects RDH12 from degradation}

In a previous study, we have shown that exposure to bright light induces a specific decrease of RDH12 protein level in the mouse retina while the closely related RDH11 protein remains stable [17]. This effect is not accompanied by a decrease of the Rdh12 mRNA level so we hypothesized that the protein reduction was due to increased degradation rather than decreased production of RDH12 [17]. We further hypothesized that RDH12, like any other protein could be modified by 4-HNE (or maybe even more so because it has specific affinity for this molecule) and targeted for degradation [17]. Bright light would increase the endogenous production of 4-HNE and modification of RDH12, and the adduct would be quickly degraded. If not compensated by an increase in RDH12 synthesis, this would result in a net decrease of RDH12.

We used mouse retinal explants to test this hypothesis (Figure 5). Incubation of mouse retinas in a media containing 4 -HNE leads to a $40 \%$ decrease of RDH12 in $4 \mathrm{~h}$, while RDH12 level remains stable in retinas incubated in the same media without 4-HNE (Figure 5A). Total 4-HNE-modified proteins were then immunoprecipitated with anti-HNE antibody and immunoblotted using an RDH12 antibody. RDH12 was immunoprecipitated by the antiHNE antibody (Figure 5B), demonstrating the modification of RDH12 by 4-HNE. The 4HNE-RDH12 adduct accumulates first (at 1 and $2 \mathrm{~h}$ incubation with 4-HNE) and then decreases (at 4 and $6 \mathrm{~h}$ incubation with 4-HNE), supporting the hypothesis that the adduct is targeted for degradation. When compared with the total amount of 4-HNE-modified protein, the modification of RDH12 does not seem to happen significantly faster than the modification of the other proteins (Figure 5C). This result invalidates the idea that the specific affinity of RDH12 for 4-HNE would increase the rate of adduct formation. By contrast, the decrease of 4-HNE-RDH12 adduct is significantly faster than the decrease of the total amount of 4-HNE-modified protein (Figure 5C). This result suggests that RDH12 is particularly unstable (compared with other proteins) when subjected to oxidative modification. 
A.

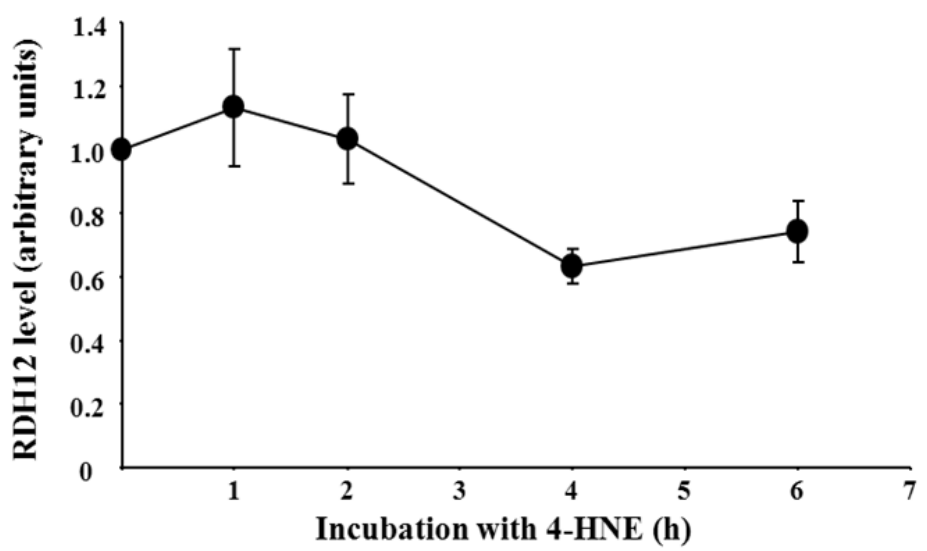

B.

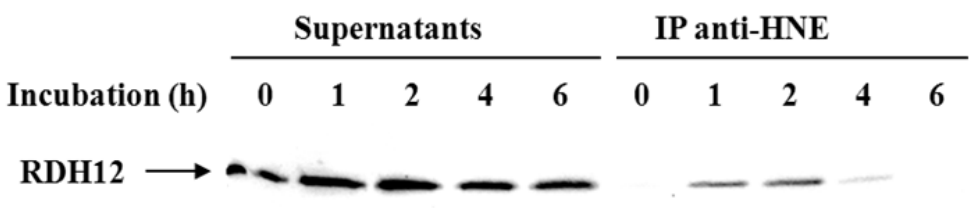

C.

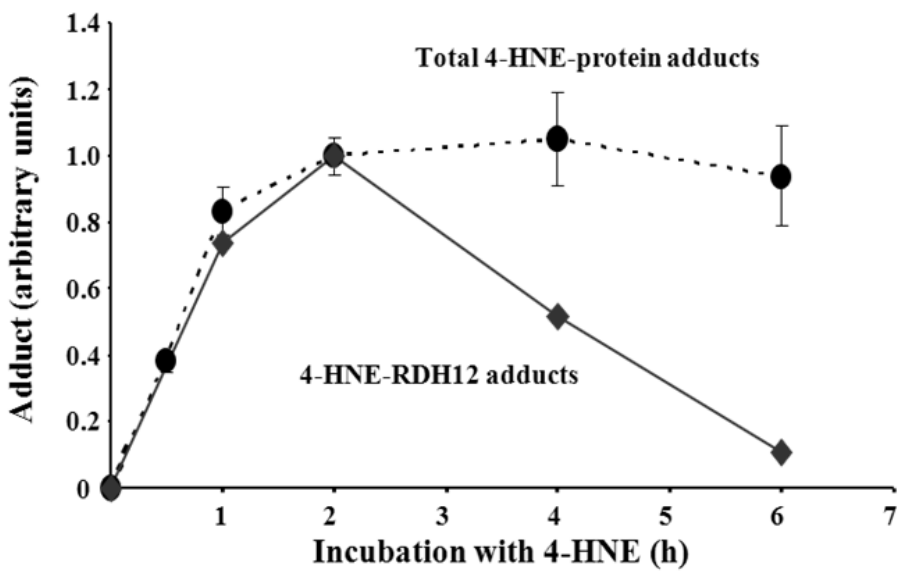

Fig. 5. 4-HNE modifies RDH12 and induces its degradation in retinal explants. Retinas were dissected from 4- to 6-weeks-old pigmented wild-type mice. Retinas were incubated in Dulbecco's modified Eagle's medium, with or without $200 \mu \mathrm{M} 4-\mathrm{HNE}$, at $37^{\circ} \mathrm{C}$ under $5 \% \mathrm{CO}_{2}$. 
At indicated times, 6 retinas were removed from incubation, immediately washed in phosphate buffered saline, and frozen in liquid nitrogen for subsequent protein preparation. Frozen retinas were homogenized in T-PER buffer (Pierce), according to the manufacturer's instructions. A. Protein concentrations were measured and immunoblot analysis using antiRDH12 antibody was performed using $30 \mu \mathrm{g}$ of protein. The levels of RDH12 in retinal explants incubated with 4-HNE were expressed relative to those of RDH12 in retinal explants incubated without 4-HNE, arbitrarily defined as 1.0. B. Immunoprecipitation of 4HNE-modified proteins was carried out as follow: equal amounts of protein were pooled from 6 retinas. $100 \mu \mathrm{g}$ of pooled protein were incubated with $5 \mu \mathrm{l}$ of anti-HNE antibody coupled with biotin (abcam) over night at 4oC, in a volume of $100 \mu \mathrm{l} \mathrm{T-PER.} 50 \mu \mathrm{l}$ of streptavidin agarose resin (Pierce) was then added to each sample and incubated for $1 \mathrm{~h}$ at $4^{\circ} \mathrm{C}$. After 3 washes with $1 \mathrm{ml}$ T-PER, proteins were eluted in $50 \mu \mathrm{l}$ Laemmli buffer and immunoblot analysis of supernatant and immunoprecipitated proteins were carried out with the anti-RDH12 antibody. C. Dot blot quantification of total 4-HNE-protein adduct was carried out as described in Fig. 2. with $2.5 \mu \mathrm{g}$ of protein. The results from B were quantified and plotted on the same graph. At each time point the amounts of adducts are expressed relative to the highest level of adduct, arbitrarily defined as 1.0. Signals were detected using SuperSignal West Pico chemiluminescent or West Femto Maximum Signal Substrate (Pierce) and quantified using Kodak Molecular Imaging Software.

Interestingly, following intravitreal injection (Figure 6A) or systemic administration of carcinine (Figure 6B), the RDH12 protein level in mouse retina is stabilized and completely resistant to light-induced degradation. In vivo, the amount of 4-HNE-RDH12 adduct was undetectable (unpublished observation) so we could not determine whether carcinine was protecting RDH12 because it was opposing the 4-HNE-modification of RDH12 or through another mechanism. Absence of detectable 4-HNE-RDH12 adduct in vivo might be explained by the fact that endogenous production of 4 -HNE as well as formation and degradation of adduct is an ongoing process, by contrast with the single dose of 4-HNE applied to the retinal explants creating a detectable "pulse" of 4-HNE-RDH12 adduct.

The stabilization of RDH12 protein by carcinine could enhance its therapeutic benefits for LCA13 patients. As discussed before, the RDH12 mutants associated with LCA are not only poorly active, but are also particularly unstable. The stabilizing effect of carcinine could keep the level of mutant RDH12 high enough to allow residual RDH12 enzymatic activity in photoreceptor cells. This, in addition with 4-HNE scavenging and antioxidant properties, could preserve the retinal structure and function in LCA13 patients.

\subsection{Carcinine can be administered topically for chronic treatment}

Treatment with carcinine would have to be started at the time of diagnosis and applied chronically to protect against 4-HNE and oxidative damage, which are ongoing processes in cells. We have investigated various modes of administration that could be compatible with a chronic treatment and measured the resulting level of carcinine in the retina (manuscript submitted for publication and unpublished results). Interestingly, topical administration through eye drop leads to detectable levels of carcinine in the retina (Figure 7). This result suggests that carcinine migrates from the cornea to the retina, following topical administration. The mechanisms of migration (simple diffusion versus transport) as well as the routes of 
migration (trans-corneal versus trans-conjonctival penetration, migration through the vitreous humor or by lateral diffusion through the sclera, etc) are currently under investigation. The possibility to administer carcinine through eye drops is promising because it is a non-invasive and particularly easy route of administration, compatible with chronic treatment.

A.

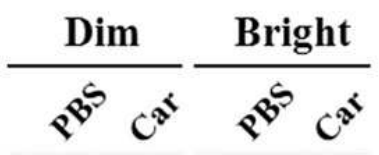

RDH12 $\rightarrow$

B.
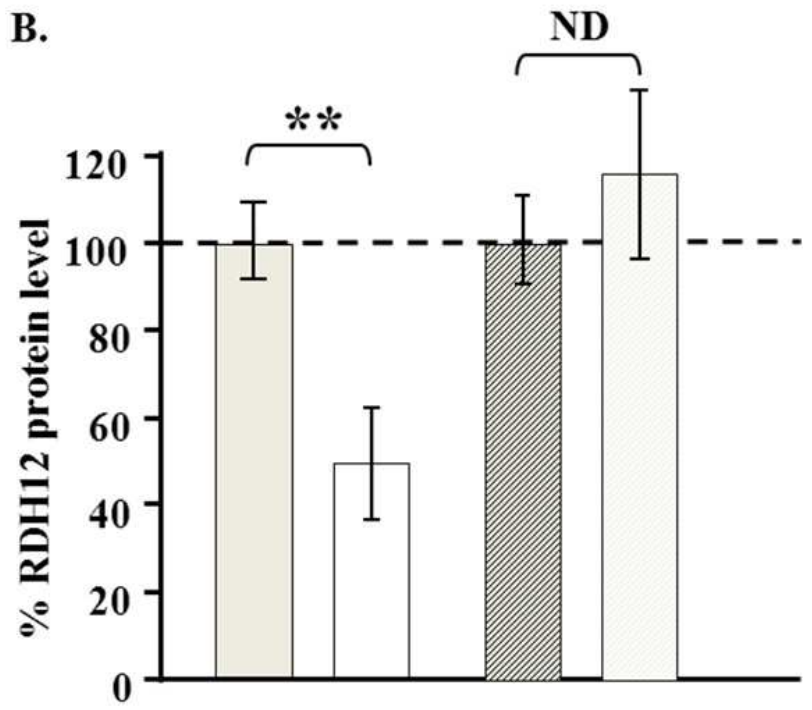

\section{Dim Bright Dim Bright \\ - carcinine+Carcinine}

Fig. 6. Carcinine protects RDH12 from light-induced degradation in mouse retina. BALB/c mice were raised in dim cyclic light for 8 weeks before carcinine treatment. A. Mice were injected with carcinine or PBS and exposed to bright light as described in Fig. 4. For each group, $10 \mu \mathrm{g}$ protein extract from 6 mice were pooled $(60 \mu \mathrm{g}$ final) and immunoblotted with anti-RDH12 antibody. B. Carcinine was administered through gavage ( 0 or $20 \mathrm{mg} /$ mouse/ day) once a day for 5 days before light exposure. Mice were then exposed to bright white fluorescent light (3,000 lux) for $4 \mathrm{~h}$. Retinas were immediately frozen and proteins were extracted from one retina from each mouse ( 4 mice per group) using T-PER reagent. Protein 
extracts from each mouse were individually quantified by immunoblot. RDH12 levels were normalized to $\beta$-actin first and expressed relative to the level of RDH12 in retinas of dim untreated mice, defined as $100 \%$. Graph shows average and SEM values for 4 mice per group. Student's $t$ test was used for significance; NS, not significant $(>0.05) ;{ }^{* *}=p<0.001$.

A.

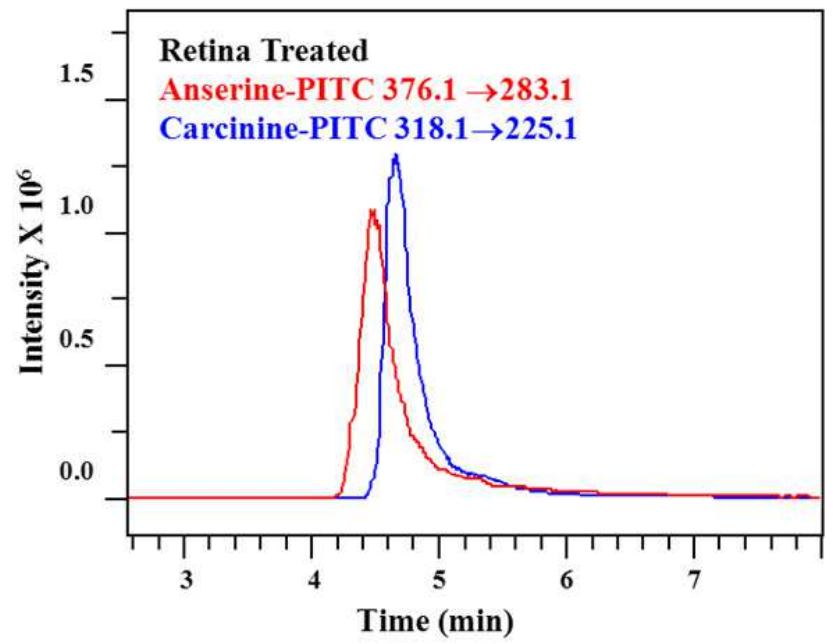

B.

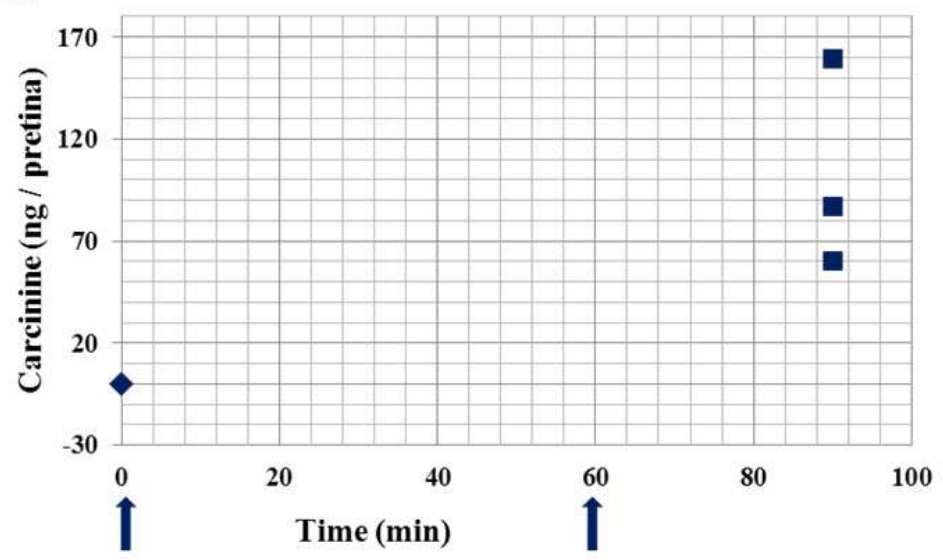

Fig. 7. Topical administration of carcinine leads to detectable levels in the retina.

Mice received carcinine $(0.2 \mathrm{M})$ dissolved in Can-C eye drop solution (Innovative Vision Products, Inc). To analyze and quantify retinal carcinine, 2 retinas were homogenized in $1 \mathrm{ml}$ of cold $0.01 \mathrm{M} \mathrm{HCl}$ with polytron. One $\mu \mathrm{g}$ of internal standard anserine was added to the samples. Samples were extracted with acetonitrile and derivatized with phenylisothiocyanate (PITC). Samples were analyzed by high-performance liquid chromatography / mass spectrometry 
(Michrom Bioresources Paradigm MSRB capillary HPLC, Bruker Daltonics HCT Ultra Ion trap MS). High-performance liquid chromatography was run on column Magic MS C18, 5m, 200 A, $0.5 \times 150 \mathrm{~mm}$ with Solvent A (0.09\% formic acid, $0.01 \%$ TFA, $2 \%$ acetonitrile, $97.9 \%$ water) and Solvent B (0.09\% formic acid, $0.0085 \%$ TFA, $95 \%$ acetonitrile, $4.9 \%$ water). An isocratic program (15\% B for $10 \mathrm{~min}$ ) was used. The flow rate was $20 \mathrm{ml} / \mathrm{min}$ and detection wavelength was $215 \mathrm{~nm}$. An ion trap mass spectrometer (HCT Ultra PTM discovery system, Bruker Daltonics) equipped with an electrospray ion source and operating under an Esquire data analysis system was used. The spray voltage was set at $4 \mathrm{kV}$ in the positive mode. The heater temperature was maintained at $300^{\circ} \mathrm{C}$. A, $0.2 \mathrm{M}$ carcinine was administered in Can-C eye drop solution at $0 \mathrm{~min}$ and mice were killed $30 \mathrm{~min}$ later to collect retinas. B, Another set of mice received $0.2 \mathrm{M}$ carcinine at 0 and $60 \mathrm{~min}$ (indicated by arrows) and were killed $30 \mathrm{~min}$ following the second administration (at $90 \mathrm{~min}$ ) to collect retinas.

\section{A. Dim cyclic light}

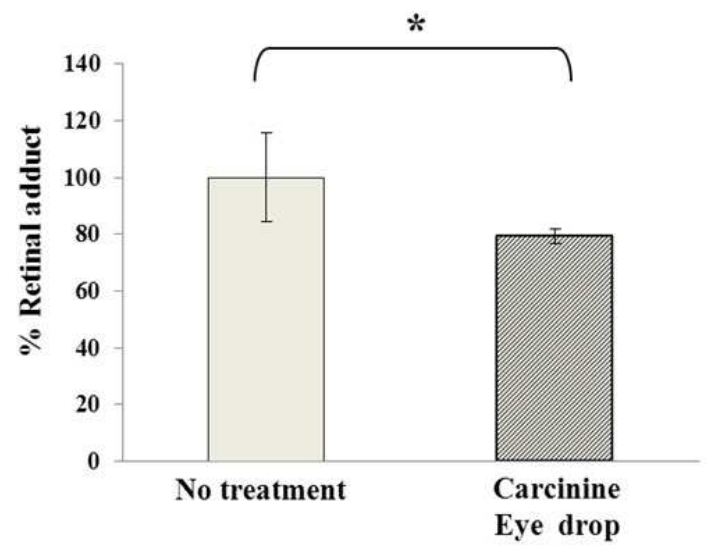

\section{B. Bright light}

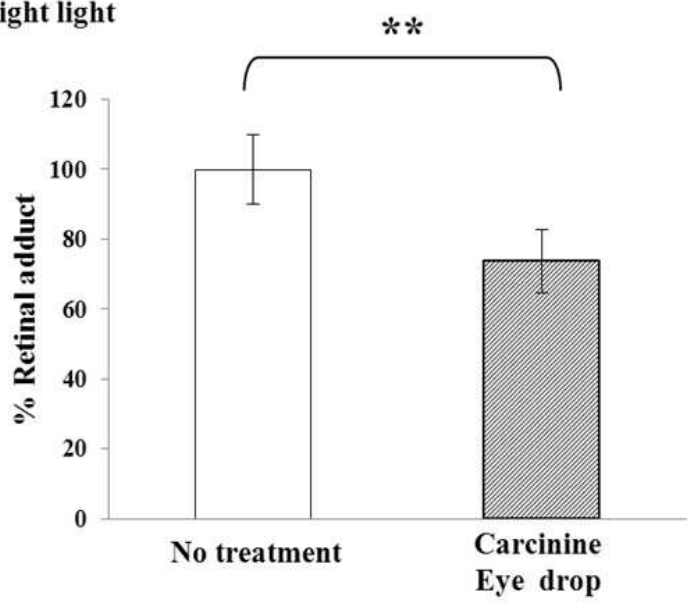

Fig. 8. Carcinine decreases total 4-HNE-modified protein in mouse retina. BALB/c mice were raised in dim cyclic light for 8 weeks before carcinine treatment. $0.2 \mathrm{M}$ carcinine was 
administered in Can-C eye drop solution (1 drop each $60 \mathrm{~min}$, for $6 \mathrm{~h}$ ) and mice were kept in dim light (A) or exposed to bright light (3,000 lux) for $4 \mathrm{~h}$, starting right after administration of the second drop (B). Immediately after exposure to bright light, retinas were collected.

Whole retinal homogenates were prepared and equal aliquots $(10 \mu \mathrm{g})$ of retinal homogenates were analyzed by dot blot using anti-HNE coupled with HRP to quantify total 4-HNE-protein adduct. Five mice were used in each group, and the mean and SEM are plotted. Values were compared using Student's $t$ test for significance; ${ }^{*}=p<0.05$; ${ }^{* *}=p<0.001$.

\subsection{Carcinine decreases the amount of 4-HNE-protein adduct in the retina}

After administration of carcinine through eye drop, we found that the total amount of protein modified by 4-HNE in mouse retina is significantly decreased, both under dim and bright light (Figure 8 ). This result suggests that carcinine can scavenge 4-HNE in vivo after topical administration through eye drop. This implies that carcinine levels within the retina are adequate and that carcinine can enter the retinal cells to scavenge 4-HNE produced endogenously. Thus, carcinine could prevent the accumulation of toxic 4-HNE in RDH12mutant retinas. We predict that carcinine, administered through eye drops, will prevent light-induced retinal damage in the wild-type and $R d h 12$ knockout but these experiments have not been completed at this time.

\section{Future directions}

\subsection{Developing therapeutic strategies}

As shown by our preliminary experiments with carcinine, it is possible to start developing appropriate therapeutic strategies from the information already available on the function of RDH12. As discussed, exposure to bright light, as well as increased all-trans retinal levels, and increased oxidative damage particularly through 4-HNE modification are suspected to play a role in the disease mechanism. Accordingly, protection against these triggers can be developed with the goal to protect the retinal structure at least long enough to allow LCA13 patients to be eligible for gene replacement therapy.

\subsubsection{Protection from light-induced damage}

As discussed, the Rdh12 knockout photoreceptors are more sensitive than the wild-type photoreceptors to light damage in mouse and exposure to bright light might be a trigger for the early dysplastic retinal response in LCA13 patients. Therefore, protection against lightinduced retinal damage is an appropriate strategy.

Physical protection from bright light by wearing sun glasses should be encouraged for patients with LCA13. Compounds such as retinoid-like small molecules that provide chemical protection against light-induced retinal damage could also be beneficial [48, 49]. A number of studies have identified that photobleaching of rhodopsin is the essential trigger for retinal light damage [50,51]. Genetically-modified mice that lack the opsin apoprotein or that have the opsin apoprotein but lack the ability to generate 11-cis-retinal are both protected against light damage [50-52]. A steady state rhodopsin level is achieved by the balance between its bleaching and regeneration. Therefore, the rate of rhodopsin regeneration is an important factor in light damage susceptibility. Fast regeneration of 
functional rhodopsin after bleaching increases retinal sensitivity to light damage, whereas slowing the flux of retinoids through the visual cycle increases the resistance of photoreceptors to light-induced insult. For example, slowing rhodopsin regeneration and inhibiting the visual cycle with 13-cis-retinoic acid prevents light damage in albino rats [53]. More recently, it has been shown that retinylamine provides efficient protection from light damage through a similar mechanism [48].

Most of the small molecules inhibiting the visual cycle are structurally similar to retinoids [49]. However, we recently identified a-phenyl-N-tert-butyl nitrone, a commonly used free radical spin trap, as another type of compound with no structural similarity with retinoids that interferes with rhodopsin regeneration during continuous illumination and protects against light-induced retinal degeneration [54]. The advantage that a-phenyl-N-tert-butyl nitrone may have over these retinol-related compounds is that it is not structurally similar nor a derivative of any of the visual cycle components and therefore may not have adverse effect by interacting with retinoid receptors and other components of the visual cycle.

\subsubsection{Protection from oxidative damage}

Because oxidative damage is likely to contribute to the LCA13 disease mechanism, compounds that inhibit oxidative damage or enhance endogenous protection against oxidative damage would be appropriate candidates for LCA13 treatment.

A wide variety of antioxidants are available as oral supplementations. Specific advantages of carcinine would be to combine antioxidant and 4-HNE scavenging activities. Thus, carcinine can offer an additional line of defense against oxidative damage by decreasing 4HNE, a secondary product of oxidative stress that mediates and amplify the oxidative damage triggered by reactive oxygen species and that was shown to accumulate in mouse retina in absence of RDH12.

In addition, the main limitation for therapeutic utilization of antioxidants in retinal diseases is usually the poor targeting of the posterior segment of the eye (choroid, retinal pigmented epithelium, and retina) due to anatomical and physiological barriers that normally protect the eye. Most molecules cannot reach the posterior segment tissues upon topical administration in the form of eye drops. Periocular or intravitreal injections are more efficient routes of administration but they are invasive procedures, which are not compatible with a chronic preventive treatment. Oral supplementation of antioxidants is usually preferred but oral bioavailability and the necessity to cross the blood-retinal barrier limits the amount of compound reaching the target tissues, and therefore limits the prevention of oxidative damage in these tissues.

Carcinine is one of the very few compounds that can reach posterior segment tissues upon topical administration (less than 10 of such compounds have been reported to date) [55]. This method of administration represents the great advantages of being non-invasive, safer because it is used locally no systemic side effects are expected, and cheaper because it is used locally the amount needed is smaller than with systemic administration than any other methods. It is also compatible with a chronic treatment that could be administered by the patients themselves, or by their parents.

Drugs that upregulate the body's natural defense against oxidative stress would also be appropriate. Reactive oxygen species are constantly generated in cells as unwanted by- 
products of aerobic metabolism. A wide variety of enzymatic as well as non-enzymatic cellular defense systems prevents and repair reactive oxygen species-induced damage to tolerable levels. Under ideal circumstances, the rate of production of oxidative damage should be comparable to that of its removal or repair. In LCA13, absence of the cellular defense mediated by RDH12 could perhaps be compensated by the enhancement of other cellular cytoprotective mechanisms through dietary or pharmaceutical manipulations. A wide variety of dietary polyphenols and other classes of phytochemicals have been reported to induce the expression of enzymes involved in cellular antioxidant defenses and detoxification mechanisms [56]. Such compounds would be appropriate candidates for LCA13 treatment as well.

\section{Conclusion}

Although generally described in the literature as an enzyme involved in all-trans retinal reduction, in this chapter we presented evidences for an additional detoxification role of RDH12 in photoreceptor inner segments, reducing the 4-HNE produced by lipid oxidation that takes place constantly in mouse retina. Loss of this function in patients with inherited retinal dystrophy due to mutations in $\mathrm{RDH} 12$ might contribute to the dramatic and early onset loss of retinal structure and function in these individuals. Our preliminary experiments with carcinine show that this compound might be beneficial in LCA13 because it has antioxidant, 4-HNE scavenging, and RDH12 stabilizing effects in the retina. In addition, we showed that carcinine can be conveniently administered through eye drops to target the retina. Additional therapeutic strategies are developed for protection against bright light and all-trans retinal toxicity. Finally, the recent impressive clinical accomplishment of gene therapy for LCA2 patients laid the ground for using similar approaches to treat various types of LCA, including LCA13.

\section{Acknowledgment}

The authors thank Dr. Debra A. Thompson for her critical review of this manuscript. This work was supported by grants from the National Center for Research Resources (P20RR017703), the National Eye Institute (R21EY018907 and P30EY012190), the Oklahoma Center for the Advancement of Science and Technology, the University of Oklahoma College of Medicine Alumni Association, and by an unrestricted Grant from Research to Prevent Blindness, Inc. to the Ophthalmology Department of the University of Oklahoma Health Sciences Center.

\section{References}

[1] den Hollander, A.I., et al., Lighting a candle in the dark: advances in genetics and gene therapy of recessive retinal dystrophies. J Clin Invest, 2010. 120(9): p. 3042-53.

[2] Weleber, R.G., P.J. Francis, and K.M. Trzupek, Leber Congenital Amaurosis. GeneReviews, 2010.

[3] den Hollander, A.I., et al., Leber congenital amaurosis: genes, proteins and disease mechanisms. Prog Retin Eye Res, 2008. 27(4): p. 391-419.

[4] Stein, L., et al., Clinical gene therapy for the treatment of RPE65-associated Leber congenital amaurosis. Expert Opin Biol Ther, 2011. 11(3): p. 429-39. 
[5] Haeseleer, F., et al., Dual-substrate specificity short chain retinol dehydrogenases from the vertebrate retina. J Biol Chem, 2002. 277(47): p. 45537-46.

[6] Kavanagh, K.L., et al., Medium- and short-chain dehydrogenase/reductase gene and protein families : the SDR superfamily: functional and structural diversity within a family of metabolic and regulatory enzymes. Cell Mol Life Sci, 2008. 65(24): p. 3895-906.

[7] Janecke, A.R., et al., Mutations in RDH12 encoding a photoreceptor cell retinol dehydrogenase cause childhood-onset severe retinal dystrophy. Nat Genet, 2004. 36(8): p. 850-4.

[8] Perrault, I., et al., Retinal dehydrogenase 12 (RDH12) mutations in leber congenital amaurosis. Am J Hum Genet, 2004. 75(4): p. 639-46.

[9] Schuster, A., et al., The phenotype of early-onset retinal degeneration in persons with RDH12 mutations. Investigative ophthalmology \& visual science, 2007. 48(4): p. 1824-31.

[10] Sun, W., et al., Novel RDH12 mutations associated with Leber congenital amaurosis and conerod dystrophy: biochemical and clinical evaluations. Vision research, 2007. 47(15): p. 2055-66.

[11] Thompson, D.A., et al., Retinal degeneration associated with RDH12 mutations results from decreased 11-cis retinal synthesis due to disruption of the visual cycle. Hum Mol Genet., 2005. 14(24): p. 3865-75.

[12] Jacobson, S.G., et al., RDH12 and RPE65, visual cycle genes causing leber congenital amaurosis, differ in disease expression. Invest Ophthalmol Vis Sci, 2007. 48(1): p. 332-8.

[13] Lee, S.A., O.V. Belyaeva, and N.Y. Kedishvili, Disease-associated variants of microsomal retinol dehydrogenase 12 (RDH12) are degraded at mutant-specific rates. FEBS Lett. 584(3): p. 507-10.

[14] Belyaeva, O.V., et al., Biochemical properties of purified human retinol dehydrogenase 12 (RDH12): catalytic efficiency toward retinoids and C9 aldehydes and effects of cellular retinol-binding protein type $I$ (CRBPI) and cellular retinaldehyde-binding protein (CRALBP) on the oxidation and reduction of retinoids. Biochemistry, 2005. 44(18): p. 7035-7047.

[15] Marchette, L.D., et al., Retinol dehydrogenase 12 detoxifies 4-hydroxynonenal in photoreceptor cells. Free Radic Biol Med, 2009.

[16] Kurth, I., et al., Targeted disruption of the murine retinal dehydrogenase gene Rdh12 does not limit visual cycle function. Molecular and cellular biology, 2007. 27(4): p. 1370-9.

[17] Kanan, Y., et al., Retinol dehydrogenases RDH11 and RDH12 in the mouse retina: expression levels during development and regulation by oxidative stress. Investigative ophthalmology \& visual science, 2008. 49(3): p. 1071-8.

[18] Kanan, Y., et al., Retinoid processing in cone and Muller cell lines. Exp Eye Res, 2008. 86(2): p. 344-54.

[19] Maeda, A., et al., Retinol dehydrogenase (RDH12) protects photoreceptors from lightinduced degeneration in mice. The Journal of biological chemistry, 2006. 281(49): p. 37697-704.

[20] Parker, R.O. and R.K. Crouch, Retinol dehydrogenases (RDHs) in the visual cycle. Exp Eye Res, 2010. 91(6): p. 788-92. 
[21] Esterbauer, H., Cytotoxicity and genotoxicity of lipid-oxidation products. Am J Clin Nutr, 1993. 57(5): p. 779S-785S; discussion 785S-786S.

[22] Petersen, D.R. and J.A. Doorn, Reactions of 4-hydroxynonenal with proteins and cellular targets. Free Radic Biol Med, 2004. 37(7): p. 937-45.

[23] Uchida, K., 4-Hydroxy-2-nonenal: a product and mediator of oxidative stress. Prog Lipid Res, 2003. 42(4): p. 318-43.

[24] Uchida, K. and E.R. Stadtman, Modification of histidine residues in proteins by reaction with 4-hydroxynonenal. Proceedings of the National Academy of Sciences of the United States of America, 1992. 89(10): p. 4544-8.

[25] Esterbauer, H., R.J. Schaur, and H. Zollner, Chemistry and biochemistry of 4hydroxynonenal, malonaldehyde and related aldehydes. Free Radic Biol Med, 1991. 11(1): p. 81-128.

[26] Awasthi, Y.C., et al., Role of 4-hydroxynonenal in stress-mediated apoptosis signaling. Molecular aspects of medicine, 2003. 24(4-5): p. 219-30.

[27] Maeda, A., et al., Limited Roles of Rdh8, Rdh12 and Abca4 on All-Trans-Retinal Clearance in Mouse Retina. Invest Ophthalmol Vis Sci, 2009.

[28] Chrispell, J.D., et al., Rdh12 activity and effects on retinoid processing in the murine retina. J Biol Chem, 2009. 284(32): p. 21468-77.

[29] Kasus-Jacobi, A., et al., Characterization of mouse short-chain aldehyde reductase (SCALD), an enzyme regulated by sterol regulatory element-binding proteins. J Biol Chem, 2003. 278(34): p. 32380-9.

[30] Subramaniam, V.N., et al., Biochemical fractionation and characterization of proteins from Golgi-enriched membranes. The Journal of biological chemistry, 1992. 267(17): p. 12016-21.

[31] Saadi, A., et al., Role of photoreceptor retinol dehydrogenases in detoxification of lipid oxidation products. Studies on Retinal and Choroidal Disorders, To be published in 2012.

[32] Belyaeva, O.V., et al., Human retinol dehydrogenase 13 (RDH13) is a mitochondrial shortchain dehydrogenase/reductase with a retinaldehyde reductase activity. Febs J, 2007. 275(1): p. 138-47.

[33] Mehalow, A.K., et al., CRB1 is essential for external limiting membrane integrity and photoreceptor morphogenesis in the mammalian retina. Hum Mol Genet, 2003. 12(17): p. 2179-89.

[34] van de Pavert, S.A., et al., Crumbs homologue 1 is required for maintenance of photoreceptor cell polarization and adhesion during light exposure. J Cell Sci, 2004. 117(Pt 18): p. 416977.

[35] Babizhayev, M.A., Biological activities of the natural imidazole-containing peptidomimetics nacetylcarnosine, carcinine and L-carnosine in ophthalmic and skin care products. Life Sci, 2006. 78(20): p. 2343-57.

[36] Babizhayev, M.A., et al., L-carnosine (beta-alanyl-L-histidine) and carcinine (betaalanylhistamine) act as natural antioxidants with hydroxyl-radical-scavenging and lipidperoxidase activities. Biochem J, 1994. 304 ( Pt 2): p. 509-16. 
[37] Tanito, M., et al., Protein modifications by 4-hydroxynonenal and 4-hydroxyhexenal in lightexposed rat retina. Investigative ophthalmology \& visual science., 2005. 46(10): p. 3859-68.

[38] Organisciak, D.T., et al., Protection by dimethylthiourea against retinal light damage in rats. Investigative ophthalmology \& visual science, 1992. 33(5): p. 1599-609.

[39] Tanito, M., et al., Cytoprotective effect of thioredoxin against retinal photic injury in mice. Investigative ophthalmology \& visual science, 2002. 43(4): p. 1162-7.

[40] Tanito, M., et al., Attenuation of retinal photooxidative damage in thioredoxin transgenic mice. Neuroscience letters, 2002. 326(2): p. 142-6.

[41] Poli, G., et al., 4-hydroxynonenal: a membrane lipid oxidation product of medicinal interest. Med Res Rev, 2008. 28(4): p. 569-631.

[42] Tanito, M., M.P. Agbaga, and R.E. Anderson, Upregulation of thioredoxin system via Nrf2antioxidant responsive element pathway in adaptive-retinal neuroprotection in vivo and in vitro. Free Radic Biol Med, 2007. 42(12): p. 1838-50.

[43] Forman, H.J., Reactive oxygen species and alpha,beta-unsaturated aldehydes as second messengers in signal transduction. Ann N Y Acad Sci, 2010. 1203: p. 35-44.

[44] Cingolani, C., et al., Retinal degeneration from oxidative damage. Free Radic Biol Med, 2006. 40(4): p. 660-9.

[45] He, X., et al., Iron homeostasis and toxicity in retinal degeneration. Prog Retin Eye Res, 2007. 26(6): p. 649-73.

[46] Hollyfield, J.G., Age-related macular degeneration: the molecular link between oxidative damage, tissue-specific inflammation and outer retinal disease: the Proctor lecture. Invest Ophthalmol Vis Sci, 2010. 51(3): p. 1275-81.

[47] Kutty, R.K., et al., Induction of heme oxygenase 1 in the retina by intense visible light: suppression by the antioxidant dimethylthiourea. Proceedings of the National Academy of Sciences of the United States of America, 1995. 92(4): p. 1177-81.

[48] Maeda, A., et al., Effects of potent inhibitors of the retinoid cycle on visual function and photoreceptor protection from light damage in mice. Mol Pharmacol, 2006. 70(4): p. 12209.

[49] Travis, G.H., et al., Diseases caused by defects in the visual cycle: retinoids as potential therapeutic agents. Annual review of pharmacology and toxicology, 2007. 47: p. 469512.

[50] Humphries, M.M., et al., Retinopathy induced in mice by targeted disruption of the rhodopsin gene. Nat Genet, 1997. 15(2): p. 216-9.

[51] Grimm, C., et al., Protection of Rpe65-deficient mice identifies rhodopsin as a mediator of lightinduced retinal degeneration. Nat Genet, 2000. 25(1): p. 63-6.

[52] Redmond, T.M., et al., Rpe65 is necessary for production of 11-cis-vitamin $A$ in the retinal visual cycle. Nat Genet, 1998. 20(4): p. 344-51.

[53] Sieving, P.A., et al., Inhibition of the visual cycle in vivo by 13-cis retinoic acid protects from light damage and provides a mechanism for night blindness in isotretinoin therapy. Proc Natl Acad Sci U S A, 2001. 98(4): p. 1835-40.

[54] Mandal, M.N., et al., PBN (\{alpha\}-phenyl-N-tert-butyl nitrone) Prevents Light-induced Degeneration of the Retina by Inhibiting RPE65 Isomerohydrolase Activity. J Biol Chem.

[55] Gaudana, R., et al., Ocular drug delivery. AAPS J, 2010. 12(3): p. 348-60. 
[56] Surh, Y.J., J.K. Kundu, and H.K. Na, Nrf2 as a master redox switch in turning on the cellular signaling involved in the induction of cytoprotective genes by some chemopreventive phytochemicals. Planta Med, 2008. 74(13): p. 1526-39. 


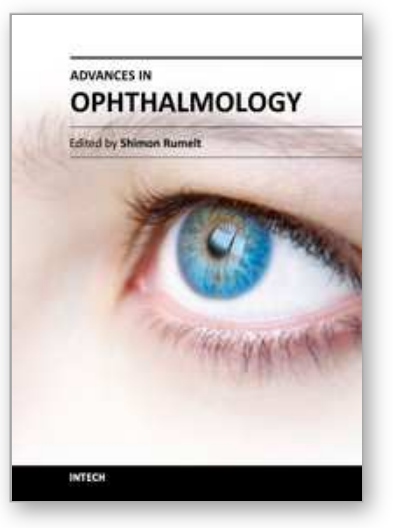

\author{
Advances in Ophthalmology \\ Edited by Dr Shimon Rumelt
}

ISBN 978-953-51-0248-9

Hard cover, 568 pages

Publisher InTech

Published online 07, March, 2012

Published in print edition March, 2012

This book focuses on the different aspects of ophthalmology - the medical science of diagnosis and treatment of eye disorders. Ophthalmology is divided into various clinical subspecialties, such as cornea, cataract, glaucoma, uveitis, retina, neuro-ophthalmology, pediatric ophthalmology, oncology, pathology, and oculoplastics. This book incorporates new developments as well as future perspectives in ophthalmology and is a balanced product between covering a wide range of diseases and expedited publication. It is intended to be the appetizer for other books to follow. Ophthalmologists, researchers, specialists, trainees, and general practitioners with an interest in ophthalmology will find this book interesting and useful.

\title{
How to reference
}

In order to correctly reference this scholarly work, feel free to copy and paste the following:

Anne Kasus-Jacobi, Lea D. Marchette, Catherine Xu, Feng Li, Huaiwen Wang and Mark Babizhayev (2012). Mechanisms of RDH12-Induced Leber Congenital Amaurosis and Therapeutic Approaches, Advances in Ophthalmology, Dr Shimon Rumelt (Ed.), ISBN: 978-953-51-0248-9, InTech, Available from: http://www.intechopen.com/books/advances-in-ophthalmology/mechanisms-of-rdh12-induced-lebercongenital-amaurosis-and-therapeutic-approaches

\section{INTECH}

open science | open minds

\section{InTech Europe}

University Campus STeP Ri

Slavka Krautzeka 83/A

51000 Rijeka, Croatia

Phone: +385 (51) 770447

Fax: +385 (51) 686166

www.intechopen.com

\section{InTech China}

Unit 405, Office Block, Hotel Equatorial Shanghai

No.65, Yan An Road (West), Shanghai, 200040, China

中国上海市延安西路65号上海国际贵都大饭店办公楼 405 单元

Phone: +86-21-62489820

Fax: +86-21-62489821 
(C) 2012 The Author(s). Licensee IntechOpen. This is an open access article distributed under the terms of the Creative Commons Attribution 3.0 License, which permits unrestricted use, distribution, and reproduction in any medium, provided the original work is properly cited. 